Pacific Journal of 


\title{
ON OPERATORS WHOSE FREDHOLM SET IS THE COMPLEX PLANE
}

\author{
M. A. KaASHOEK AND D. C. LAY
}

Let $T$ be a closed linear operator with domain and range in a complex Banach space $X$. The Fredholm set $\Phi(T)$ of $T$ is the set of complex numbers $\lambda$ such that $\lambda-T$ is a Fredholm operator. If the space $X$ is of finite dimension then, obviously, the domain of $T$ is closed and $\Phi(T)$ is the whole complex plane $C$. In this paper it is shown that the converse is also true. When $T$ is defined on all of $X$ this is a well-known result due to Gohberg and Krein.

Examples of nontrivial closed operators with $\Phi(T)=C$ are the operators whose resolvent operator is compact. A characterization of the class of closed linear operators with a nonempty resolvent set and a Fredholm set equal to the complex plane will be given.

Throughout the present paper $X$ and $Y$ will denote complex Banach spaces. Let $T$ be an arbitrary closed linear operator with domain $\mathscr{D}(T)$ in $X$ and range $\mathscr{R}(T)$ in $Y$. The nullity $n(T)$ of $T$ is the dimension of the null space $\mathscr{N}(T)$ of $T$. The defect $d(T)$ of $T$ is the dimension of the quotient space $Y / \mathscr{R}(T)$. No distinction is made between infinite dimensions, so that $n(T)$ and $d(T)$ may be nonnegative integers or $+\infty$. We say that $T$ is Fredholm if $n(T)$ and $d(T)$ are both finite. Note that $d(T)<\infty$ implies $\mathscr{R}(T)$ is closed (cf. [5], Lemma 332).

In 1957 Gohberg and Krein [3] showed that if $A$ is a bounded linear operator on $X$ with $\Phi(A)=C$, then the dimension of $X$ (denoted by $\operatorname{dim} X)$ is finite. The following theorem extends this result.

Theorem 1. Let $T$ and $S$ be bounded linear operators from $X$ into $Y$. Suppose that $S$ is a homeomorphism, and that $T+\lambda S$ is Fredholm for each $\lambda \in \boldsymbol{C}$. Then

$$
\operatorname{dim} X \leqq \operatorname{dim} Y<\infty \text {. }
$$

Proof. Since $S$ is a homeomorphism, $\mathscr{R}(S)$ is closed and $n(S)=0$. By a well-known stability theorem (cf. [5], Theorem 1), this implies the existence of a positive constant $\rho$ such that for $0<|\mu|<\rho$

$$
d(S)=d(S)-n(S)=d(S+\mu T)-n(S+\mu T) .
$$

The right-hand side is finite because $S+\mu T$ is Fredholm for $\mu \neq 0$. Hence $d(S)<\infty$, and so $S$ has a bounded left inverse, say $R$. Then $n(R) \leqq d(S)<\infty$ and $d(R)=0$, so $R$ is Fredholm. Define $A=R T$. 
Then $A$ is a bounded linear operator on $X$ and

$$
\lambda-A=\lambda R S-R T=R(\lambda S-T) .
$$

For each complex value of $\lambda, \lambda-A$ is the product of two bounded Fredholm operators and hence is Fredholm. But $\Phi(A)=C$ implies that $\operatorname{dim} X<\infty$ by the result of Gohberg and Krein ([3], Theorem 3.2). Then $\operatorname{dim} Y=\operatorname{dim} X+d(S)<\infty$, concluding the proof.

COROLlary. Let $T$ be a closed linear operator with domain $\mathscr{D}(T)$ and range in $X$. Then $\operatorname{dim} X<\infty$ if and only if $\mathscr{D}(T)$ is closed and $\Phi(T)=\boldsymbol{C}$.

In [1] Caradus has proved that if $T$ is a closed linear operator with domain and range in $X$ such that $\operatorname{dim} X / \mathscr{D}(T)<\infty, \Phi(T)=C$ and such that the resolvent set of $T$ is neither empty nor the whole complex plane, then $\operatorname{dim} X<\infty$. The following lemma shows that Caradus' result is contained in the Corollary.

Lemma. Let $T$ be a closed linear operator with domain in $X$ and range in $Y$. Suppose there exists a closed subspace $M$ of $X$ such that $X=\mathscr{D}(T) \oplus M$. Then $\mathscr{D}(T)$ is closed.

Proof. Let $Y_{1}$ be the Banach space $Y \times M$, with the norm

$$
\|(y, m)\|=\|y\|+\|m\| \text {. }
$$

Define the linear operator $J$ from $X$ into $Y$, by setting

$$
J(x+m)=(T x, m)
$$

for each $x \in \mathscr{D}(T)$ and $m \in M$. It is easily verified that $J$ is a welldefined closed linear operator. Since the domain of $J$ is the Banach space $X$, the closed graph theorem implies that $J$ is bounded. Hence

$$
(\|T x\|+\|m\|) \leqq\|\boldsymbol{J}\| \cdot\|x+m\|
$$

for each $x \in \mathscr{D}(T)$ and $m \in M$. In particular,

$$
\|T x\| \leqq\|J\| \cdot\|x\|
$$

for each $x \in \mathscr{D}(T)$. Thus $T$ is both closed and bounded, implying that $\mathscr{D}(T)$ is closed.

We have learned recently that similar statements for the range of a closed linear operator are proved by S. Goldberg in [4]. That this can be done follows easily from the observation that the range of a closed linear operator is always the domain of some other closed linear operator, and conversely (cf. [6], Chapter IV). 
The Corollary states that the closed linear operators $T$ with closed domain and $\Phi(T)=C$ are trivial. Examples of nontrivial closed operators whose Fredholm set is the complex plane are the operators with compact resolvent (cf. [7], §2). The following theorem shows that each closed operator $T$ with a nonempty resolvent set $\rho(T)$ and with $\Phi(T)=C$ is characterized by the fact that for each $\mu \in \rho(T)$ the resolvent $(\mu-T)^{-1}$ is a Riesz operator. For the definition of Riesz operators and one of their characterizations we refer to Dieudonné ([2], XI. 4, problem 5).

THEOREM 2. Let $T$ be a closed linear operator with domain and range in $X$. If $\Phi(T)=C$, then $(\mu-T)^{-1}$ is a Riesz operator for all $\mu \in \rho(T)$. Conversely, if $(\mu-T)^{-1}$ is a Riesz operator for some $\mu \in \rho(T)$, then $\Phi(T)=C$.

Proof. We may assume that $\operatorname{dim} X=\infty$ and that $\rho(T)$ is not empty. Take $\mu$ in $\rho(T)$ and let $A=(\mu-T)^{-1}$. Then for $\lambda \neq \mu$,

$$
(\lambda-T)(\mu-T)^{-1}=(\mu-\lambda)(\zeta-A),
$$

where $\zeta=(\mu-\lambda)^{-1}$. This implies that $\Phi(T)=C$ if and only if $\Phi(A)=$ $C \backslash\{0\}$. Hence it is enough to show that $A$ is a Riesz operator if and only if $\Phi(A)=C \backslash\{0\}$. In order to do this, let $\mathscr{C}$ be the ideal of all compact linear operators in the Banach algebra $\mathscr{L}(X)$ of all bounded linear operators on $X$, and let $\pi$ denote the canonical homomorphism from $\mathscr{L}(X)$ onto the quotient algebra $\mathscr{L}(X) / \mathscr{K}$. Then it follows from Atkinson's characterization of the class of all Fredholm operators in $\mathscr{L}(X)$ that $\zeta-A$ is Fredholm if and only if $\zeta-\pi(A)$ has an inverse in $\mathscr{L}(X) / \mathscr{K}$. So $\Phi(A)=C \backslash\{0\}$ if and only if the spectrum of $\pi(A)$ in $\mathscr{L}(X) / \mathscr{K}$ is $\{0\}$, i.e., the spectral radius $r(\pi(A))$ of $\pi(A)$ is zero. But

$$
\begin{aligned}
r(\pi(A)) & =\lim _{n \rightarrow \infty}\left\|[\pi(A)]^{n}\right\|^{1 / n} \\
& =\lim _{n \rightarrow \infty}\left\|\pi\left(A^{n}\right)\right\|^{1 / n}=\lim _{n \rightarrow \infty}\left[d\left(A^{n}, \mathscr{K}\right)\right]^{1 / n},
\end{aligned}
$$

where $d\left(A^{n}, \mathscr{K}\right)$ is the infimum of $\left\|A^{n}-K\right\|$ for $K \in \mathscr{K}$. Thus $\Phi(A)=C \backslash\{0\}$ if and only if

$$
\lim _{n \rightarrow \infty}\left[d\left(A^{n}, \mathscr{K}\right)\right]^{1 / n}=0,
$$

which is equivalent to the statement that $A$ is a Riesz operator (cf. [2], XI. 4, problem 5).

When $T$ is a self-adjoint closed linear operator in a Hilbert space Theorem 2 can be strengthened. This is because $(\mu-T)^{-1}$ is normal for $\mu \in \rho(T)$, and a normal operator is Riesz if and only if it is compact. 
Hence, in this special case, $\Phi(T)=C$ if and only if $(\mu-T)^{-1}$ is compact for each $\mu$ in $\rho(T)$.

\section{REFERENCES}

1. S. R. Caradus, On a theorem of Gohberg and Krein, (to be published)

2. J. Dieudonné, Foundations of Modern Analysis, Academic Press, New York, 1960.

3. I. C. Gohberg and M. G. Krein, The basic propositions on defect numbers, root numbers and indices of linear operators, Uspekhi Math. Nauk. 12, (2) 74 (1957), 43118 (Russian). Amer. Math. Soc. Transl. (2) 13 (1960), 185-265.

4. S. Goldberg, Unbounded Linear Operators: Theory and Applications, McGraw-Hill, New York, 1966.

5. T. Kato, Perturbation theory for nullity, deficiency and other quantities of linear operators, J. Analyse Math. 6 (1958), 261-322.

6. D. C. Lay, Studies in spectral theory using ascent, descent, nullity and defect, Doctoral dissertation, University of California, Los Angeles, January 1966.

7. J. T. Schwartz, Perturbations of spectral operators, and applications $I$. Bounded perturbations, Pacific J. Math. 4 (1954), 415-458.

Received March 28, 1966. This paper was written while the first author was supported by the Netherlands Organization for the Advancement of Pure Research (Z.W.O.) under a Postdoctoral Fellowship.

University of CALifornia, Los ANGeles 


\section{PACIFIC JOURNAL OF MATHEMATICS}

\section{EDITORS}

H. SAMELSON

Stanford University

Stanford, California

J. P. JANS

University of Washington

Seattle, Washington 98105

\section{J. DugunduI}

University of Southern California Los Angeles, California 90007

RICHARD ARENS

University of California

Los Angeles, California 90024

\section{ASSOCIATE EDITORS}
E. F. BECKENBACH
B. H. NEUMANN
F. WOLF
K. YoSIDA

\section{SUPPORTING INSTITUTIONS}

\author{
UNIVERSITY OF BRITISH COLUMRIA \\ CALIFORNIA INSTITUTE OF TECHNOLOGY \\ UNIVERSITY OF CALIFORNIA \\ MONTANA STATE UNIVERSITY \\ UNIVERSITY OF NEVADA \\ NEW MEXICO STATE UNIVERSITY \\ OREGON STATE UNIVERSITY \\ UNIVERSITY OF OREGON \\ OSAKA UNIVERSITY \\ UNIVERSITY OF SOUTHERN CALIFORNIA
}

\author{
STANFORD UNIVERSITY \\ UNIVERSITY OF TOKYO \\ UNIVERSITY OF UTAH \\ WASHINGTON STATE UNIVERSITY \\ UNIVERSITY OF WASHINGTON \\ AMERICAN MATHEMATICAL SOCIETY \\ CHEVRON RESEARCH CORPORATION \\ TRW SYSTEMS \\ NAVAL ORDNANCE TEST STATION
}

Mathematical papers intended for publication in the Pacific Journal of Mathematics should be typewritten (double spaced). The first paragraph or two must be capable of being used separately as a synopsis of the entire paper. It should not contain references to the bibliography. Manuscripts may be sent to any one of the four editors. All other communications to the editors should be addressed to the managing editor, Richard Arens at the University of California, Los Angeles, California 90024 .

50 reprints per author of each article are furnished free of charge; additional copies may be obtained at cost in multiples of 50 .

The Pacific Journal of Mathematics is published monthly. Effective with Volume 16 the price per volume (3 numbers) is $\$ 8.00$; single issues, $\$ 3.00$. Special price for current issues to individual faculty members of supporting institutions and to individual members of the American Mathematical Society: $\$ 4.00$ per volume; single issues $\$ 1.50$. Back numbers are available.

Subscriptions, orders for back numbers, and changes of address should be sent to Pacific Journal of Mathematics, 103 Highland Boulevard, Berkeley 8, California.

Printed at Kokusai Bunken Insatsusha (International Academic Printing Co., Ltd.), No. 6, 2-chome, Fujimi-cho, Chiyoda-ku, Tokyo, Japan.

\section{PUBLISHED BY PACIFIC JOURNAL OF MATHEMATICS, A NON-PROFIT CORPORATION}

The Supporting Institutions listed above contribute to the cost of publication of this Journal, but they are not owners or publishers and have no responsibility for its content or policies. 


\section{Pacific Journal of Mathematics}

\section{Vol. 21, No. 2 December, 1967}

Arne P. Baartz, The measure algebra of a locally compact semigroup ..... 199

Robert F. Brown, On maps with identical fixed point sets............. 215

C. Buttin, Existence of a homotopy operator for Spencer's sequence in the analytic case ..................................... 219

Henry Werner Davis, An elementary proof that Haar measurable almost periodic functions are continuous ........................ 241

Zeev Ditzian, On asymptotic estimates for kernels of convolution transforms ...................................... 249

Robert E. Edwards, Boundedness principles and Fourier theory ......... 255

John A. Hildebrant, On compact unithetic semigroups ............... 265

Marinus A. Kaashoek and David Clark Lay, On operators whose Fredholm set is the complex plane ............................ 275

Sadao Kató, Canonical domains in several complex variables ........... 279

David Clifford Kay, The ptolemaic inequality in Hilbert geometries.... . . . 293

Joseph D. E. Konhauser, Biorthogonal polynomials suggested by the Laguerre polynomials ............................. 303

Kevin Mor McCrimmon, Macdonald's theorem with inverses .......... 315

Harry Eldon Pickett, Homomorphisms and subalgebras of multialgebras .................................... 327

Richard Dennis Sinkhorn and Paul Joseph Knopp, Concerning nonnegative matrices and doubly stochastic matrices ..............

Erling Stormer, On anti-automorphisms of von Neumann algebras ...

Miyuki Yamada, Regular semi-groups whose idempotents satisfy permutation identities .......................... 